\title{
Hospitalisation of the elderly during the last year of life: an application of record linkage in Western Australia 1985-1994
}

\author{
Kate J Brameld, C D’Arcy J Holman, A John Bass, Jim P Codde, Ian L Rouse
}

\begin{abstract}
Study objective-To measure the trend, pattern, and cost of time spent in hospital during the last year of life in Western Australia and to identify trends in the place of death. The results were compared with those reported from the Oxford Record Linkage Study.

Design-Mortality records for those aged 65 years and over were linked to inpatient hospital morbidity records with a date of separation within one year before death. Comparative inpatient resource utilisation was estimated using ANDRG 3.0 cost weights for Australian public hospitals.
\end{abstract}

Setting-Western Australia.

Participants-All 68875 persons aged 65 years and over who died between 1 January 1985 and 31 December 1994.

Main results-Increasing proportions of all age groups (65-74, 75-84, and 85+ years) were admitted to hospital at least once in the year before death during 198594, but the chance of admission decreased with age. There was a trend towards a greater number of shorter admissions per person. Total bed days per person showed no significant increase, except at ages 65-74 years. Total inpatient resource utilisation during the last year of life was lowest and remained constant in those aged 85 years and over, while increasing gradually (3.7\% per annum) in the younger elderly. The Western Australian population spent more time in hospital in the last year of life at ages 65-74 years, but the advanced elderly spent less time in hospital, when compared with the Oxford Region.

Conclusions-Recent gains in life expectancy and higher per capita health expenditure have not been accompanied by more time spent in hospital during the last year of life at ages $75+$ years. International 24 April 1998

Table 1 Proportion of age groups admitted to hospital at least once in the year before death in 1994, broken down by total number of bed days

\begin{tabular}{|c|c|c|c|c|}
\hline \multirow[b]{2}{*}{ Total bed days per person } & \multicolumn{3}{|l|}{ Age group } & \multirow[b]{2}{*}{$\begin{array}{l}\text { Total } \\
(n=7606) \\
(\%)\end{array}$} \\
\hline & $\begin{array}{l}65-74 \\
(n=2235) \\
(\%)\end{array}$ & $\begin{array}{l}75-84 \\
(n=3028) \\
(\%)\end{array}$ & $\begin{array}{l}85+ \\
(n=2343) \\
(\%)\end{array}$ & \\
\hline Not admitted & 17.1 & 20.4 & 32.7 & 23.2 \\
\hline$<7$ & 18.5 & 18.0 & 16.3 & 17.6 \\
\hline $7-13$ & 11.2 & 10.1 & 8.8 & 10.0 \\
\hline $14-27$ & 17.6 & 16.0 & 13.0 & 15.6 \\
\hline $28-89$ & 29.1 & 28.5 & 22.9 & 26.9 \\
\hline $90-179$ & 5.9 & 5.6 & 4.5 & 5.4 \\
\hline $180-364$ & 0.3 & 0.8 & 1.0 & 0.7 \\
\hline$\geqslant 365$ & 0.3 & 0.6 & 0.8 & 0.6 \\
\hline Total & 100.0 & 100.0 & 100.0 & 100.0 \\
\hline
\end{tabular}

differences between Western Australia and Oxford can be explained by differences in aged care provision.

(F Epidemiol Community Health 1998;52:740-744)

Life expectancy at the age of 65 years has increased in Western Australia by 1.5 years to 81.0 years in men and by 1.2 years to 85.0 years in women over the 10 year period to 1994. It has been suggested that increases in life expectancy may be accompanied by a "compression of morbidity", ${ }^{1}$ with consequent shrinkage in the requirement for medical care during the later years. The alternate view is that there is a prolonged time during which people may experience ill health and thus an increase in the demand for medical care. This study uses record linkage to measure the trend, pattern, and cost of time spent in hospital during the last year of life in Western Australia, to identify trends in the place of death, and to see if during a period of increased life expectancy, and higher per capita expenditure on health care in Australia, ${ }^{2}$ there has been more time spent in hospital during the last year of life. We also compare these results with those reported from the Oxford Record Linkage Study. ${ }^{3}$

\section{Methods}

The State of Western Australia occupies the western third of the Australian continent and has a population of 1.7 million. A linked file of population-based inpatient hospital morbidity and death records was obtained from the Western Australian Health Services Research Linked Database for the period 1984-1994 (Holman CDJ, Rouse IL, Bass AJ, Hobbs MST, unpublished). Records were selected for all people aged 65 years and over who died between 1 January 1985 and 31 December

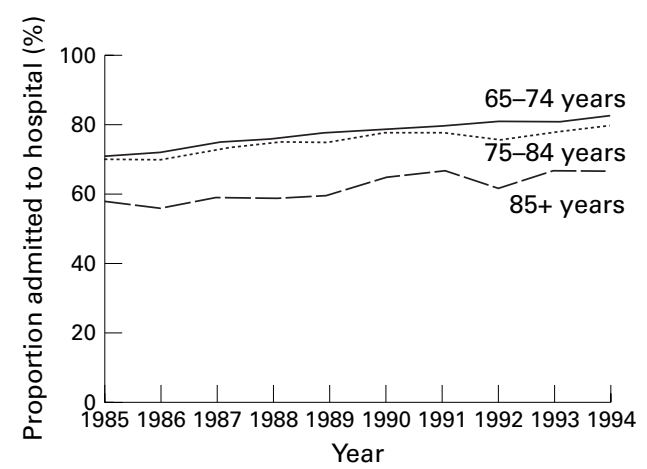

Figure 1 Proportion of persons by age admitted to hospital at least once in the year before death from 1985 to 1994. 
Table 2. Average number of admissions per person and average length of stay per admission in the last year of life from 1985 to $1994^{*}$

\begin{tabular}{|c|c|c|c|c|c|c|}
\hline \multirow[b]{2}{*}{ Year } & \multicolumn{3}{|c|}{$\begin{array}{l}\text { Average number of admissions per } \\
\text { person }\end{array}$} & \multicolumn{3}{|c|}{$\begin{array}{l}\text { Average length of stay per } \\
\text { admission }\end{array}$} \\
\hline & $65-74$ & $75-84$ & $85+$ & $65-74$ & $75-84$ & $85+$ \\
\hline 1985 & 2.9 & 2.6 & 1.9 & 12.6 & 15.0 & 25.5 \\
\hline 1986 & 3.2 & 2.6 & 2.1 & 11.2 & 15.3 & 21.7 \\
\hline 1987 & 3.1 & 2.6 & 2.1 & 11.3 & 15.1 & 22.3 \\
\hline 1988 & 3.4 & 2.5 & 2.2 & 10.1 & 14.8 & 17.7 \\
\hline 1989 & 3.7 & 2.7 & 2.3 & 9.7 & 14.2 & 18.6 \\
\hline 1990 & 3.8 & 3.1 & 2.3 & 9.2 & 12.4 & 16.8 \\
\hline 1991 & 4.2 & 3.0 & 2.4 & 8.2 & 11.9 & 15.8 \\
\hline 1992 & 4.0 & 3.1 & 2.4 & 8.6 & 12.1 & 15.9 \\
\hline 1993 & 4.3 & 3.3 & 2.5 & 8.2 & 10.7 & 15.0 \\
\hline 1994 & 4.3 & 3.2 & 2.5 & 8.0 & 11.7 & 15.7 \\
\hline Mean change per year & +0.17 & +0.09 & +0.06 & -0.50 & -0.53 & -1.06 \\
\hline p Value & 0.0001 & 0.0002 & 0.0001 & 0.0001 & 0.0001 & 0.0003 \\
\hline
\end{tabular}

${ }^{\star}$ This table excludes patients who were not admitted to hospital during their last year of life.

1994. Age was taken to be that given on the death record. Within each chain of records pertaining to an individual, linked hospital morbidity records were selected if the date of separation occurred within the year before death or the patient died in hospital. During the 10 year study period there were 68875 deaths and 152022 hospital admissions within the last year of life. Admission may have occurred at any one of the State's 95 public and 35 private hospitals.

The proportion of the population admitted to hospital at least once in the year before death was calculated. Total bed days spent in hospital during the year before death were calculated by summing the lengths of stay of all admissions. If two admissions overlapped, as with certain types of interhospital transfer, then only one overall time period of hospitalisation was counted. Where a patient was admitted before, but discharged after the date exactly one year before death, only the bed days occurring within one year of death were counted. Average length of stay per admission was also calculated. Trends over time were calculated by fitting regression lines to the annual data points.

The introduction of diagnosis related groups (DRGs) during 1988 and their associated cost weights enabled a comparison of inpatient resource utilisation. The average cost weights were calculated for both individual and total admissions per person in the last year of life, based on ANDRG version 3.0 for Australian public hospitals. ${ }^{4}$ This analysis was only

Table 3 Mean bed days per person spent in hospital in the last year of life from 1985 to $1994^{\star}$

\begin{tabular}{llll}
\hline \multicolumn{4}{c}{ Age group } \\
\cline { 2 - 4 } Year & $65-74$ & $75-84$ & $85+$ \\
\hline 1985 & 25 & 27 & 28 \\
1986 & 26 & 27 & 26 \\
1987 & 26 & 28 & 27 \\
1988 & 26 & 28 & 23 \\
1989 & 28 & 29 & 26 \\
1990 & 27 & 30 & 26 \\
1991 & 27 & 28 & 26 \\
1992 & 28 & 29 & 24 \\
1993 & 29 & 27 & 25 \\
1994 & 28 & 29 & 26 \\
Mean change per year & +0.35 & +0.16 & -0.20 \\
p Value & 0.0004 & 0.1681 & 0.2171 \\
\hline
\end{tabular}

*This table includes patients who were not admitted to hospital during their last year of life.
KEY POINTS

- An increasing proportion of the elderly population are being admitted to hospital in their last year of life.

- A decrease in average length of stay has been accompanied by an increase in the number of admissions.

- Total resource utilisation in hospital was lowest and remained constant over time in those aged $85+$ years.

- The proportion of people aged 75 and over who died in hospital showed no decline.

- International differences in hospitalisation patterns between Western Australia and the Oxford Region can be explained by differences in community and residential care.

performed for those who died in 1991-94, because DRGs first became available in the West Australian Hospital Morbidity Data System in mid-1989. The trend over time was calculated by fitting a regression line to the average annual cost.

Place of death was assigned, using the "place of death" text and code given on the death record, into one of four categories: hospital; other institution (nursing homes, hostels and longstay mental institutions); home; and "other" (other private dwellings, public places and en route to hospital). Cause of death was analysed using the cause of death code (ICD-9).

\section{Results}

ADMISSIONS IN THE YEAR BEFORE DEATH

Increasing proportions of all elderly age groups were admitted to hospital at least once in the year before death (fig 1). The "young" elderly were more likely to be admitted than those aged 85 years and over. Of those who were admitted, just under one half spent 28 or more days in hospital (table 1). Those aged over 74 years were 2-3 times more likely than their younger counterparts to spend more than six months in hospital.

LENGTH OF STAY AND TOTAL BED DAYS

Satellite dialysis was reclassified from outpatient episodes to same-day admissions in 1990. As this would be expected to increase the

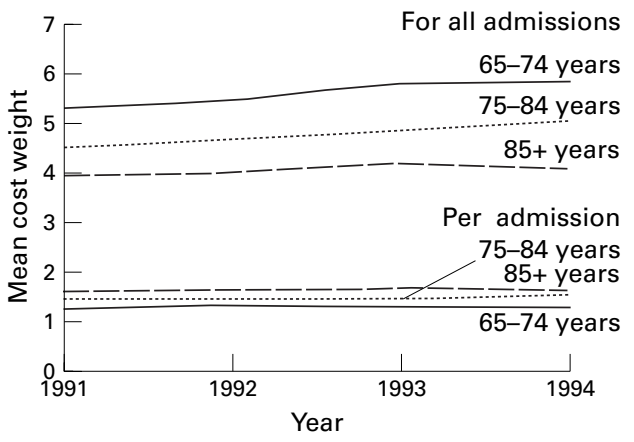

Figure 2 Mean DRG cost weight per admission and the sum for all admissions for an individual in the last year of life from 1991 to 1994. 
Table 4 Place of death of the elderly by age group in the last year of life

\begin{tabular}{|c|c|c|c|c|c|c|c|c|c|}
\hline \multirow[b]{3}{*}{ Year } & \multirow[b]{3}{*}{ Place of death } & \multicolumn{6}{|c|}{ Age group } & & \\
\hline & & \multicolumn{2}{|l|}{$65-74$} & \multicolumn{2}{|l|}{$75-84$} & \multicolumn{2}{|l|}{$85+$} & \multicolumn{2}{|l|}{ Total } \\
\hline & & Number & $\%$ & Number & $\%$ & Number & $\%$ & Number & $\%$ \\
\hline \multirow[t]{5}{*}{1985} & Hospital & 1238 & 60 & 1448 & 53 & 549 & 38 & 3235 & 52 \\
\hline & Other institution & 251 & 12 & 737 & 27 & 760 & 53 & 1748 & 28 \\
\hline & Home & 480 & 23 & 454 & 17 & 119 & 8 & 1053 & 17 \\
\hline & Other & 107 & 5 & 82 & 3 & 14 & 1 & 201 & 3 \\
\hline & Total & 2076 & 100 & 2721 & 100 & 1442 & 100 & 6239 & 100 \\
\hline \multirow[t]{5}{*}{1990} & Hospital & 1144 & 56 & 1548 & 53 & 789 & 43 & 3481 & 52 \\
\hline & Other institution & 233 & 12 & 737 & 26 & 866 & 47 & 1836 & 27 \\
\hline & Home & 545 & 27 & 526 & 18 & 156 & 9 & 227 & 18 \\
\hline & Other & 106 & 5 & 91 & 3 & 18 & 1 & 215 & 3 \\
\hline & Total & 2028 & 100 & 2902 & 100 & 1829 & 100 & 6759 & 100 \\
\hline \multirow[t]{5}{*}{1994} & Hospital & 1197 & 53 & 1574 & 52 & 893 & 38 & 3664 & 48 \\
\hline & Other institution & 335 & 15 & 891 & 29 & 1214 & 52 & 2440 & 32 \\
\hline & Home & 603 & 27 & 490 & 16 & 215 & 9 & 1308 & 17 \\
\hline & Other & 100 & 5 & 73 & 3 & 21 & 1 & 194 & 3 \\
\hline & Total & 2235 & 100 & 3028 & 100 & 2343 & 100 & 7606 & 100 \\
\hline
\end{tabular}

number of admissions per person, reduce the average length of stay per admission, and increase the total bed days during the last year of life, the results were calculated with and without satellite dialysis patients. This caused very little difference and therefore the results in tables 2 and 3 are presented without satellite dialysis admissions. In fact, satellite dialysis admissions accounted for less than $0.1 \%$ of total bed days in 1994 .

The number of admissions per person in the last year of life increased in all age groups, but was accompanied by a decrease in the average length of stay per admission (table 2). Average length of stay per admission increased with older age. Total bed days per person increased slightly in those aged 65-74 years, remained fairly constant in the 75-84 year age group, and showed a small, non-significant decrease in those aged over 84 years (table 3 ).

INPATIENT RESOURCE UTILISATION

The mean DRG cost weight per admission during the last year of life remained relatively constant in all age groups during the period 1991-94 (fig 2). The cost weight per admission increased moderately with age, whereas the cost weights summed across all admissions for an individual in the last year of life decreased with age.

There was a slight increase in the average cost weight per admission of $4.0 \%$ per calendar year at ages $65-74$ years $(b=+0.19 ; p=0.042)$ and $3.3 \%$ at ages $75-84$ years $(b=+0.19 ; \mathrm{p}=$ 0.0001 ), while there was little or no evidence of increase at ages $85+$ years $(b=+0.07 ; \mathrm{p}=$ $0.270)$. The effect for all age groups combined was an average $3.1 \%$ per annum increase $(b=$ +0.15; $\mathrm{p}=0.018$ ) during 1991-94 (fig 2).

CAUSE OF DEATH

Admission patterns of the elderly in their last year of life were dominated by people dying from either cancer or circulatory disease. Patients with circulatory disease were less likely than those with cancer to be admitted to hospital (30\% not admitted versus $5 \%$ of cancer patients). Moreover, $48 \%$ of cancer patients spent longer than 28 days in hospital compared with only $26 \%$ of patients with circulatory disease.
PLACE OF DEATH

Over $50 \%$ of deaths in those aged $65-84$ years occurred in hospital, whereas most deaths at ages $85+$ years occurred in other institutions such as nursing homes and hostels (table 4). The proportion of elderly people dying at home decreased with age. A decreasing proportion of the 65-74 year age group died in hospital, but the proportion aged 75 or more years dying in hospital remained constant.

\section{Discussion}

The results show that although an increasing proportion of the West Australian elderly were hospitalised in their last year and the pattern of hospitalisation shifted from fewer long stays to more frequent shorter stays, the total time spent in hospital per person showed no significant increase in those aged over 74 years and was not indicative of the population becoming increasingly ill during their last year of life, although in the younger elderly there was a gradual increase in inpatient resource utilisation over time.

Admission of the elderly to hospital depends on a number of factors besides their physical and mental health. These include the availability of family and social support, community care services, alternative forms of residential care, hospital admission policies, and availability of beds. ${ }^{3}$ A further factor that may cause an increase in the number of admissions could be the rising expectation of patients about the health care to which they are entitled. ${ }^{5}$

The results show that an increasing proportion of the Western Australian elderly population is admitted to hospital during their last year of life, but that the likelihood of admission decreases with age. Similar results have been reported from Oxford. ${ }^{3}$ Explanations for the increasing number of admissions include improvements in health care provision to the elderly, changing criteria for referral and surgery and, possibly, an increase in the prevalence of some conditions. ${ }^{56}$

There are a number of possible explanations for why the advanced elderly are less likely to be admitted to hospital during their last year of life. They may have survived to advanced old age because of the absence of chronic illness ("compression of morbidity"). 
Table 5 Number of days spent in hospital by the elderly in the final year of life in Western Australia and the Oxford Region* in 1985 (percentages of people in each age group)

\begin{tabular}{|c|c|c|c|c|c|c|}
\hline \multirow[b]{3}{*}{ Total bed days per person } & \multicolumn{6}{|l|}{ Age group } \\
\hline & \multicolumn{2}{|l|}{$65-74$} & \multicolumn{2}{|l|}{$75-84$} & \multicolumn{2}{|l|}{$85+$} \\
\hline & $\begin{array}{l}W A \\
(n=2076) \\
\%\end{array}$ & $\begin{array}{l}\text { Oxford } \\
(n=4447) \\
\%\end{array}$ & $\begin{array}{l}W A \\
(n=2721) \\
\%\end{array}$ & $\begin{array}{l}\text { Oxford } \\
(n=6742) \\
\%\end{array}$ & $\begin{array}{l}W A \\
(n=1442) \\
\%\end{array}$ & $\begin{array}{l}\text { Oxford } \\
(n=3998) \\
\%\end{array}$ \\
\hline Not admitted & 29.4 & 29.3 & 30.4 & 28.5 & 42.2 & 36.7 \\
\hline$<7$ & 17.7 & 19.5 & 16.5 & 17.7 & 16.9 & 12.5 \\
\hline $7-13$ & 9.0 & 13.4 & 8.7 & 12.1 & 7.0 & 9.1 \\
\hline $14-27$ & 13.8 & 16.3 & 15.3 & 15.2 & 10.1 & 12.8 \\
\hline $28-89$ & 24.3 & 17.5 & 22.7 & 18.7 & 16.6 & 18.6 \\
\hline $90-179$ & 4.3 & 2.6 & 4.6 & 4.1 & 3.5 & 4.5 \\
\hline $180-364$ & 1.0 & 0.9 & 0.9 & 1.8 & 1.3 & 2.5 \\
\hline$\geqslant 365$ & 0.5 & 0.4 & 1.0 & 1.6 & 2.4 & 3.3 \\
\hline Total & 100.0 & 100.0 & 100.0 & 100.0 & 100.0 & 100.0 \\
\hline \multicolumn{7}{|l|}{ Mean bed days per person } \\
\hline In those admitted & 36 & 29 & 39 & 42 & 48 & 59 \\
\hline Overall & 25 & 21 & 27 & 30 & 28 & 37 \\
\hline Proportion dying in hospital (\%) & 59.6 & 54.0 & 53.2 & 58.7 & 38.1 & 49.8 \\
\hline
\end{tabular}

^As reported by Henderson et al. ${ }^{3}$

A higher proportion of the advanced elderly live in residential care and, therefore, their threshold for hospital admission may be higher ("substitution of care"). ${ }^{7} \mathrm{~A}$ further possibility is that medical or surgical intervention in this group may be considered inappropriate because of their advanced age ("age-dependent rationing"). ${ }^{3}$

However, of those who are admitted, the advanced elderly are more likely to spend six months or more in hospital during their last year of life. This may reflect a slower recovery time in this group of patients or a higher discharge threshold as the patients are less able to look after themselves and appropriate placement in residential care may be delayed.

A decrease in the average length of stay per admission over time has been observed in Manitoba, ${ }^{8}$ the United States, ${ }^{9}$ and Oxford. ${ }^{6}{ }^{10}$ These trends may be related both to changing medical practice, improvements in the quality of hospital care, and economic restraint. On one hand increasing use of same-day surgery and outpatient and community based treatment programmes lead to a genuine reduction in the amount of time required in hospital. ${ }^{11} \mathrm{On}$ the other hand, economic pressures and changes in methods of funding also promote early patient discharge. This raises concern about whether the decrease is achieved by remediation of inefficiencies in health care delivery or whether it represents a cost saving contingent upon a reduced quality of care. The Rand study of North America evaluated quality of care before and after the introduction of casemix funding for five specific conditions and found that although length of stay fell by $24 \%$, readmission rates remained unchanged and there was no adverse effect on death rates. ${ }^{9}$

Henderson $\mathrm{et} \mathrm{al}{ }^{3}{ }^{3}$ studied hospital care of the elderly during their last year of life in the Oxford Region in 1976-1985. A selection of their results are compared with those of the present Western Australian study in table 5, taking 1985 as the common year for comparison. The Oxford population aged 85 years and over were more likely than their West Australian counterparts to be admitted to hospital during their last year of life. Oxford 65-74 year olds were equally likely to be admitted to hos- pital as those from Western Australia, but a lower proportion of them had total stays exceeding four weeks. The difference was less marked in the 75-84 year age group. Total bed days during the last year of life were higher in Oxford for those aged over 85 years, similar in both populations for the 75-84 year age group, and lower at 65-74 years in Oxford. With regard to place of death, the 65-74 year age group was less likely to die in hospital in Oxford, but those aged 75 years and over were less likely to die in hospital in Western Australia.

These disparities may result from a longer existing community care plan in England than in Australia. As a result there are a greater number of nursing home places per head of population in Australia as compared with England. In 1985, there were 67 nursing home beds and 32 hostel places per 1000 population aged $70+$ years in Western Australia, giving a total of 99 residential places per 1000 population. ${ }^{7}$ In contrast, in England and Wales, where "care in the community" has been government policy since the 1960 s, there were 79 residential places per 1000 population aged $75+$ years in $1986 .{ }^{12}$ Thus, short hospital stays followed by discharge to a community care service is probably more common in the UK, whereas in Western Australia, the threshold for hospital admission is probably higher, particularly in the advanced elderly, because of the greater prevalence of advanced elderly already in residential care.

Comparison of total bed days in the last year of life and of the proportion of the two populations dying in hospital is consistent with the above theory. Western Australia may have fewer people aged $85+$ years spending much of the last year of life in hospital because they are more likely to be in receipt of residential care and thus less likely to require long stay admission to hospital. In contrast the young elderly, the 65-74 year age group, may spend less time in hospital in Oxford because the greater availability of community care enables an earlier discharge. Admission rates to nursing homes and hostels are much lower in this age group and are unlikely to moderate the numbers of West Australian patients admitted to hospital. 
The place of death of the elderly depends on their state of health before death, the presence or absence of disease and the severity of the disease. For those with terminal illness, place of death is affected by availabilities of hospital beds, residential care, and palliative home care. Where possible, health services should help patients to die in their preferred setting. Studies that have investigated the issue of preferred place of death of terminally ill patients have found that over $50 \%$ of patients would prefer to die at home if possible. ${ }^{13-15}$

Western Australia has a hospice palliative care service that began in 1982. During 1994 95, they cared for 1729 terminally ill patients in the metropolitan area, of whom 1158 (67\%) were aged 65 years and over. ${ }^{16}$ The penetrance of the hospice palliative care service had been estimated at around $71 \% .{ }^{16}$ This indicates that the hospice palliative care service were involved in the care of around 15\% of elderly people who died and that a further $6 \%$ of the elderly could benefit from their care. These figures do not include those receiving palliative care services in the country or informal services such as those provided by general practitioners as no data were available.

A complete study of health care costs would include hospital outpatients, primary medical care, community-based services, and residential care as well as hospital care. Most studies of this nature have suggested that those who die at an older age incur fewer hospital and physician expenses than those who die at a younger age, ${ }^{171}$ with the exception of Roos et $a l,{ }^{19}$ in Manitoba, who found that those dying at age 85 years and over incurred greater expenses than those dying at a younger age. In our cost weight analysis the total inpatient resource utilisation during the last year of life decreased with age and the increase in cost over the 10 year period was smallest for those aged 85 years and over. It therefore seems unlikely that an excessive amount of high cost care is delivered to elderly patients with a poor prognosis.

Our results confirm those of the Oxford Study, ${ }^{3}$ that the gain in life expectancy "was not at the expense of any substantial increase in time spent in hospital in the year before death".
We thank those who maintain the West Australian Hospital Morbidity Data System and the West Australian Health Services Research Linked Data Base. Dr Michael Hobbs provided helpful review of the manuscript.

Funding: The Lotteries Commission of Western Australia and The Health Department of Western Australia.

1 Fries JM. Aging, natural death, and the compression of morbidity. N Engl f Med 1980;303:130-5.

2 Australia's health services expenditure, 1982-83 to 1994-95. Canberra: Australian Institute of Health and Welfare, 1996.

3 Henderson J, Goldacre MJ, Griffith M. Hospital care for the elderly in the final year of life: a population based study. BMF 1990;301:17-19.

4 Report on the development of ANDRG version 3.0 cost weights. Canberra: Commonwealth Department of Human Services and Health, 1995.

5 Goldacre MJ, Simmons H, Henderson J, et al. Trends in the episode based and person based rates of admission to hospital in the Oxford record linkage study area. BMF 1988;296:583-5.

6 Ferguson JA, Goldacre MJ, Henderson J, et al. Ophthalmology in the Oxford Region: analysis of time trends from linked statistics. Eye 1991;5:379-84.

7 Mathur S. Aged care services in Australia's states and territories. Canberra: Australian Institute of Health and Welfare, 1996.

8 Harrison ML, Graff LA, Roos NP, et al. Discharging patients earlier from Winnipeg Hospitals: Does it adversely affect quality of care? Can Med Assoc f 1995;153:745-51.

9 Kahn KL, Keeler EB, Sherwood MJ, et al. Comparing outcomes of care before and after implementation of the DRG-based prospective payment system. FAMA 1990; 264:1984-8.

10 Goldacre MJ, Ferguson JA. In-patient workload in medical specialties: 1. Demographic profiles and time trends from linked statistics. QF Med 1995;88:649-59.

11 Weinberg J. The impact of ageing upon the need for medical beds: a Monte-Carlo simulation. F Public Health Med 1995; 17:290-6.

12 Darton $\mathrm{R}$, Wright $\mathrm{K}$. Changes in the provision of long-stay care, 1970-1990. Health and Social Care in the Community $1993 ; 1: 11-25$.

13 Townsend J, Frank AO, Fermont D, et al. Terminal cancer care and patients' preference for place of death: a prospective study. BMF 1990;301:415-17.

14 McWhinney IR, Bass MJ, Orr V. Factors associated with location of death (home or hospital) of patients referred to a palliative care team. Can Med Assoc f 1995;152:361-7.

15 Dunlop RJ, Davies RJ, Hockley JM. Preferred versus actual place of death: a hospital palliative care support team experience. Palliat Med 1989;3:197-201.

16 WA Hospice Palliative Care Working Group. Palliative Care in Western Australia to the year 2001. Part One. Metropolitan in Western Australia to the year 2001. Part One. Metropolitan Area.

17 Temkin-Greener H, Meiners MR, Petty EA, et al. The use and cost of health services prior to death: A comparison of the Medicare-only and the Medicare-Medicaid elderly populations. Milbank Q 1992;70:679-701.

18 Scitovsky AA. Medical care in the last twelve months of life: The relation between age, functional status, and medical care expenditures. Milbank $Q$ 1988;66:640-60.

19 Roos NP, Montgomery P, Roos LL. Health care utilization in the years prior to death. Milbank $Q$ 1987;65:231-54 